\title{
MICROSTRUCTURAL FEATURES OF MULTILAYER WELDS WITH DIFFERENT HOT CRACKING SENSITIVITY*
}

\author{
K.A. YUSHCHENKO, L.I. MARKASHOVA, A.V. ZVYAGINTSEVA, YU.A. KHOKHLOVA, \\ O.S. KUSHNARYOVA and N.O. CHERVYAKOV
}

E.O. Paton Electric Welding Institute, NASU

11 Kazimir Malevich Str., 03680, Kiev, Ukraine. E-mail: office@paton.kiev.ua

\begin{abstract}
The work deals with multilayer welds made with Inconel 52 wire, which have a high sensitivity to formation of hot ductility dip cracks in the heat-affected zone, and welds made with 52MSS wire, which turned out to be insensitive to formation of this type of cracks at a certain level of strain rates. Changes of structural characteristics of welds made with the above wires were studied by the methods of transmission microscopy, X-ray microprobe analysis, microhardness measurement, as well as electron backscatter diffraction. 9 Ref., 2 Tables, 8 Figures.
\end{abstract}

Keywords: multilayer surfacing, ductility dip cracks, nickel alloys, dislocation density, stacking fault energy, microhardness

Prediction and control of structure and properties of metallic materials and welded structures from them require multilevel hierarchic approach to the solid body, as a totality of interrelated subsystems, such as electron subsystem; crystalline lattice, the structure of which is determined by electron subsystem; subsystem of crystalline lattice defects; surface layers; all inner interfaces; individual phase subsystems in complex heterogeneous media [1].

At present, plotting of multilevel model of deformed solid is in the active stage of its development. Main characteristics of individual subsystems, their functional relationships, regularities of their selfconsistent change in different fields of external impact (mechanical, thermal, electric, radiation, etc.) are experimentally studied.

This work deals with structural changes under the impact of welding cycle for multilayer deposits, made with wires with different sensitivity to hot cracking.

Known is the high sensitivity to formation of ductility dip cracks (DDC) in welded joints of nickel alloys of Inconel 690 type, when cracks form in the temperature range of about $700-1000{ }^{\circ} \mathrm{C}$ along high-angle migration boundaries of austenite grains predominantly in multipass welds [2-4]. Mechanical testing in Ala-Too unit (Greeble type) showed differences in susceptibility to ductility dip formation. Welded joints performed with Inconel 52 wire have lower values of relative elongation in temperature range of $600-1000{ }^{\circ} \mathrm{C}$, unlike welded joints made with Inconel 52MSS wire, in which ductility dip in the respective temperature range is small [3].

In connection with problems, arising at assessment of welded joint properties, it was proposed to perform work on modeling the welding conditions for multipass welds in welded structures, which were made as six-pass deposits on Inconel 690 alloy plates of $(6-8) \times 40 \times 200 \mathrm{~mm}$ size into pre-planed grooves.

Table 1 gives chemical composition of welding wires and base metal.

The process of automatic groove welding proper with application of $0.9 \mathrm{~mm}$ diameter wire was performed with non-consumable electrode in argon in the following modes: $U_{\mathrm{a}}=10.5 \mathrm{~V} ; v_{\mathrm{w} . \mathrm{f}}=75 \mathrm{~m} / \mathrm{h}$;

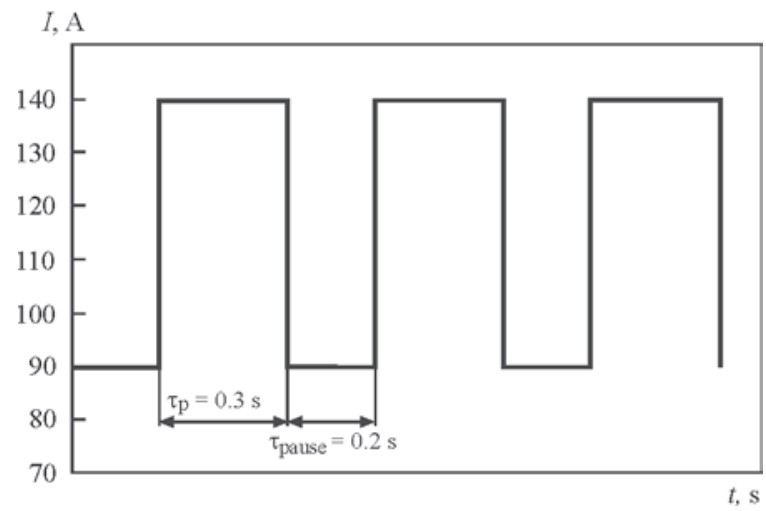

Figure 1. Automatic welding modes

\footnotetext{
*Based on materials of the work performed under purpose-oriented integrated program of the NAS of Ukraine «Problems of life and safe operation of structures, constructions and machines» (2013-2015).
} 
Table 1. Chemical composition of base metal and welding wires, wt.\%

\begin{tabular}{|c|c|c|c|c|c|c|c|c|c|c|c|c|}
\hline Alloy grade & $\mathrm{C}$ & $\mathrm{Mn}$ & $\mathrm{Ni}$ & $\mathrm{Cr}$ & $\mathrm{Fe}$ & $\mathrm{Nb}$ & $\mathrm{Mo}$ & $\mathrm{Ti}$ & $\mathrm{S}$ & $\mathrm{P}$ & $\mathrm{Al}$ & $\mathrm{Si}$ \\
\hline In 690 & 0.025 & 0.24 & Base & 29.72 & 10.3 & - & - & 0.28 & 0.002 & 0.005 & 0.87 & 0.32 \\
\hline In 52 & 0.026 & 0.31 & Same & 28.80 & 8.5 & 0.03 & 0.03 & 0.51 & 0.001 & 0.004 & 0.72 & 0.12 \\
\hline In 52MSS & 0.024 & 0.29 & $»$ & 30.30 & 7.2 & 2.52 & 3.51 & 0.25 & 0.0008 & 0.0006 & 0.22 & 0.15 \\
\hline
\end{tabular}

$f_{\text {osc }}=60 \mathrm{osc} / \mathrm{min} ; A_{\text {osc }}=25 \mathrm{~mm} ; v_{\mathrm{w}}=6 \mathrm{~m} / \mathrm{h}$, shown in Figure 1.

Under these conditions, selected welding modes provided optimum formation of each bead of multilayer weld without undercuts or lacksof-penetration between the beads and minimum penetration of the previous weld.

Samples were prepared from surfaced plates (gauging and grinding to $340 \times 180 \times 3 \mathrm{~mm}$ dimensions) for respective testing in PVR-Test unit with variable straining rate during welding in the range of $0-12 \mathrm{~mm} / \mathrm{min}$. Testing procedure and results are described in [5].

As regards subsequent analysis of the conditions of development and nature of propagation of DDC in the weld made with Inconel 52MSS and Inconel 52 wires, experimental studies of grain structure in the HAZ were performed in the first stage, using scanning electron microscope with application of EDX and CCD-detector. EDX methods were used to study the chemical inhomogeneity of cellular structure of Inconel 52MSS weld metal and of Inconel 52 weld metal, unalloyed with molybdenum and niobium, for comparison (Figures 2 and 3).

Investigations showed that chemical inhomogeneity is much smaller in Inconel 52 welds, in which molybdenum and niobium content is minimum (their total content is $\sim 0.7 \%$ ), that promotes DDC formation. At the same time, in individual sections of Inconel 52MSS wire weld, niobium and molybdenum content rises $\sim 2-4$ times, compared to total content (of the order of $6 \%$ ).

At the next stage of investigations, TEM method was used to study fine (dislocation) structure of metal in different zones of welded joint, in particular substructure nature, details of intergranular, subgranular boundaries and other structural parameters. Direct transmission studies of fine structure were conducted in JEM-200CX unit (JEOL) at accelerating voltage of $200 \mathrm{kV}$. In this case, assessment of scalar density and nature of dislocation distribution (Figure 4) was performed with secant method. Here, specific values of dislocation density were found from the dependence

$$
\rho=\frac{M}{t}\left(\frac{n_{1}}{L_{1}} \div \frac{n_{2}}{L_{2}}\right),
$$

where $M, t$ are the foil magnification and thickness; $n_{1}, n_{2}$ is the number of intersections with horizontal and vertical lines, respectively; $L_{1}, L_{2}$ is the total length of horizontal and vertical lines. All the results on evaluation of dislocation density in weld metal (both at application of Inconel 52MSS and Inconel 52 wires) in different sections of the structure, namely in inner grain volumes, along intergranular, as well as subgrain boundaries, are given in Table 2 .
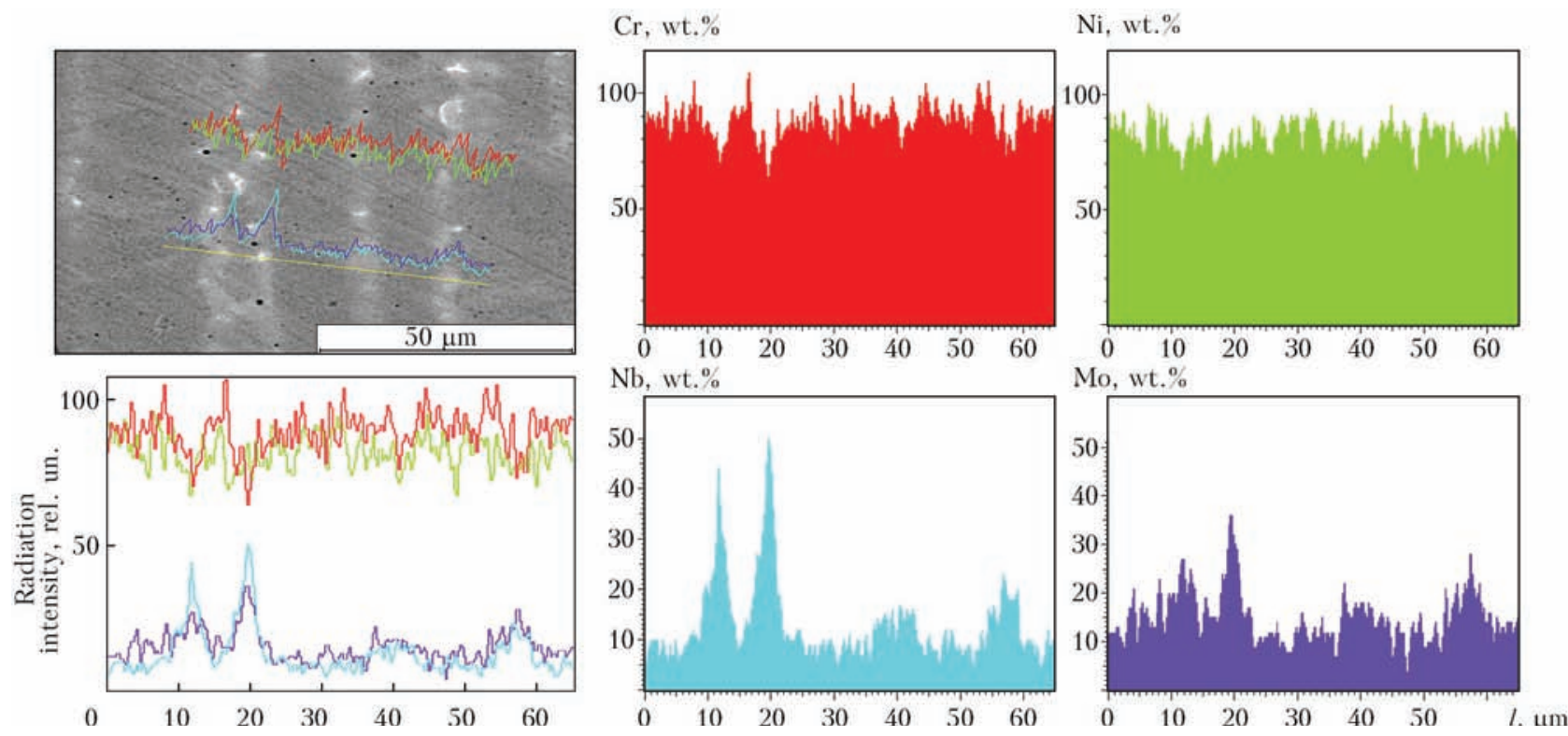

Figure 2. Concentrational changes of chemical elements in studied regions of metal of welds, made with Inconel 52MSS wire in argon, in which chemical inhomogeneity by niobium and molybdenum is observed 

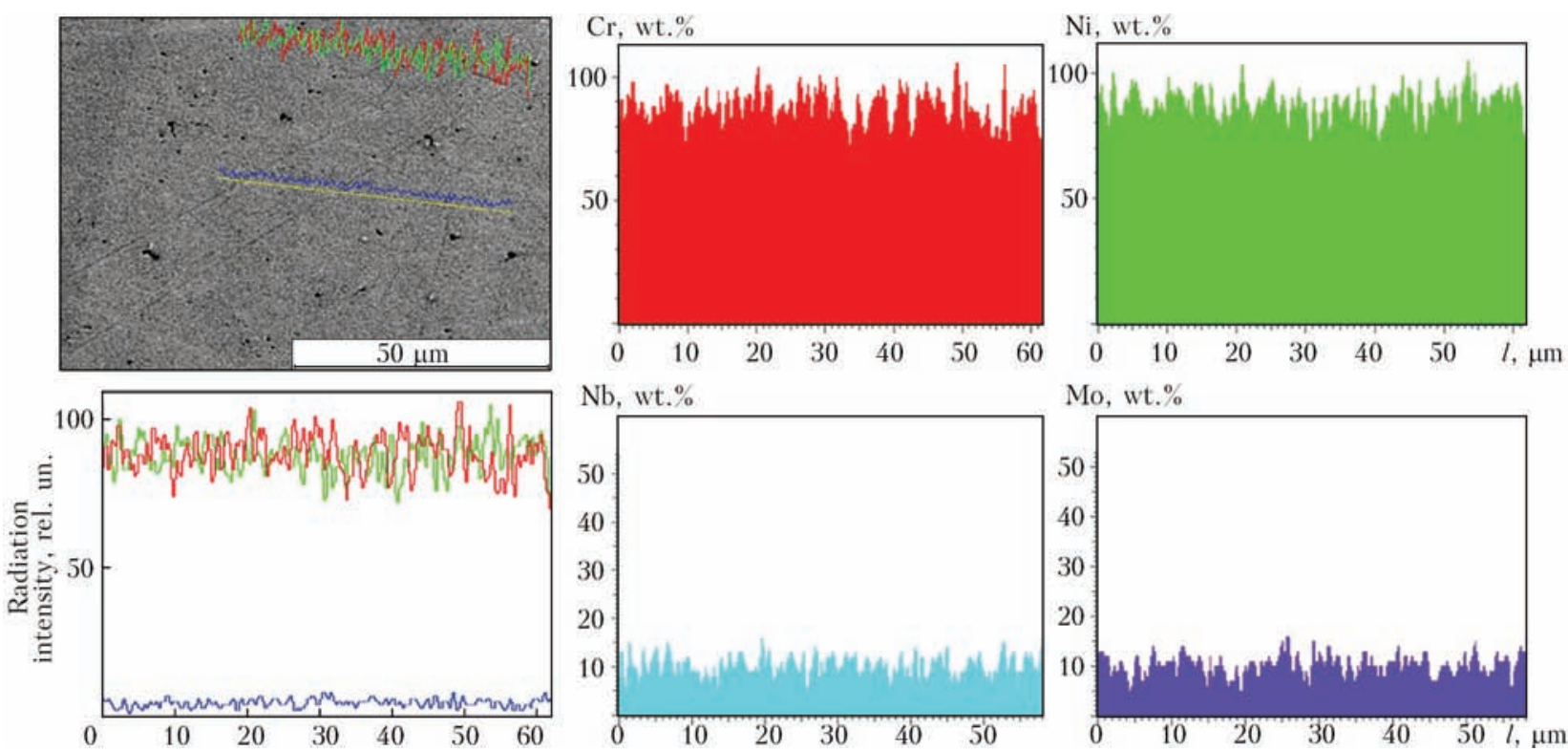

Figure 3. Concentrational changes of chemical elements in studied regions of metal of welds made, with Inconel 52 wire in argon, in which chemical inhomogeneity is not observed
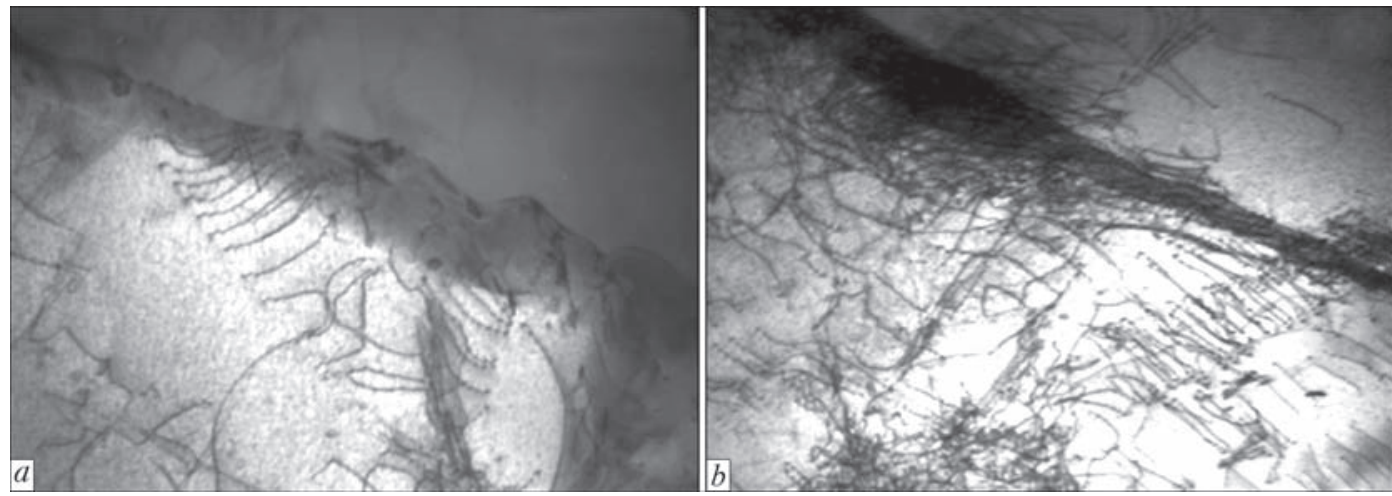

Figure 4. Nature of dislocation distribution in weld metal $(\times 30,000): a-$ uniform distribution with low density in Inconel 52MSS alloy; $b$ - greater dislocation density at its graded distribution in Inconel 52 alloy

Phase composition of precipitates forming in welding zone was determined by the methods of microdiffraction analysis.

Detailed studies of the nature of dislocation structure also allowed assessment of such defect formation parameters as stacking fault energy (SFE), which is the characteristic of the conditions of structural defect formation and can characterize hot cracking susceptibility of the studied material.

Values of SFE were determined in this case by the width of dislocation splitting, and stacking fault width was determined by direct measurement on structural images obtained at transmission studies of fine structure. Specific SFE values were given by the dependence [6-8]

$$
\gamma=\frac{\mu b^{2}(2-v)}{8 \pi d_{0}(1-v)},
$$

where $v$ is the Poisson's ratio; $b$ is the Burgers vector; $\gamma$ is the SFE; $\mu$ is the shear modulus; $d_{0}$ is the width of dislocation splitting (distance between partial dislocations).

As a result of investigations in this direction, it was established that in weld metal the width of dislocation splitting (both in the volume of grains, and at intergranular boundaries) is equal to $0.045-0.070 \mu \mathrm{m}$ at application of Inconel 52MSS wire (see Figure 4, $a$ ), that corresponds to $\gamma_{\mathrm{SFE}} \sim 0.091 \mathrm{~J} / \mathrm{m}^{2}$ (Figure 5). It should be noted here that in this weld metal increased content of $\mathrm{Mo}=3.51 \%$ and $\mathrm{Nb}=2.51 \%$ lowers the

Table 2. Dislocation density in inner grain volumes and along intergranular and subgranular boundaries of weld metal at application of wire with different alloying

\begin{tabular}{|l|c|c|}
\hline \multirow{2}{*}{$\begin{array}{c}\text { Structure } \\
\text { regions }\end{array}$} & \multicolumn{2}{|c|}{$\rho, \mathrm{cm}^{-2}$} \\
\cline { 2 - 3 } $\begin{array}{l}\text { Grain } \\
\text { volume }\end{array}$ & $10^{8}-10^{9}$ & $2 \cdot 10^{9}-8 \cdot 10^{10}$ \\
\hline $\begin{array}{l}\text { Grain } \\
\text { subboundary }\end{array}$ & $10^{9}$ & $9 \cdot 10^{10}$ \\
\hline $\begin{array}{l}\text { Grain } \\
\text { boundary }\end{array}$ & $(6-7) \cdot\left(10^{9}-10^{10}\right)$ & $\begin{array}{l}10^{11}-2.2 \cdot 10^{11} \\
(\text { rare 3.10 }\end{array}$ \\
\hline
\end{tabular}




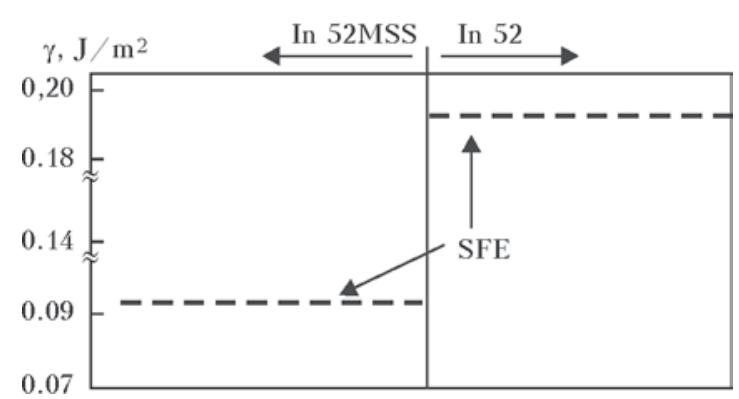

Figure 5. Change of SFE for welds at application of Inconel 52MSS and Inconel 52 wires

SFE value, which is exactly what leads to increase of crack resistance of the studied metal.

For a more detailed analysis of the nature of DDC propagation in the weld, made with Inconel 52MSS and Inconel 52 wires, experimental studies of grain structure near the crack in the HAZ were performed in the Zeiss scanning electron microscope EVO-50, with application of CCD-detector. Maps of crystallographic orientation of grains (Figure 6) for each of the studied samples are indicative of the fact that DDC in welded joint HAZ propagate along high-angle boundaries (Figure 7) that is also confirmed in [9].

As regards samples made with Inconel 52MSS wire, no cracks were found in the HAZ of this type of samples. Additional studies of the substructure showed presence of a large number of low-angle boundaries with $2-4^{\circ}$ fragment disorientation in the grain body. The low-angle boundaries are practically absent in Inconel 52 welds. Statistical studies of the sites of DDC propagation in the HAZ showed that defects of this type propagated, mainly, along grain boundaries predominantly with $<111>$ and $<101>$ orientation, or along grain boundaries with $<100>$ orientation.

Then, moduli of elasticity and microhardness were measured in grain structures with known crystallographic directions. The objective of experiment was to study the mechanical and crystallographic changes during plastic deformation

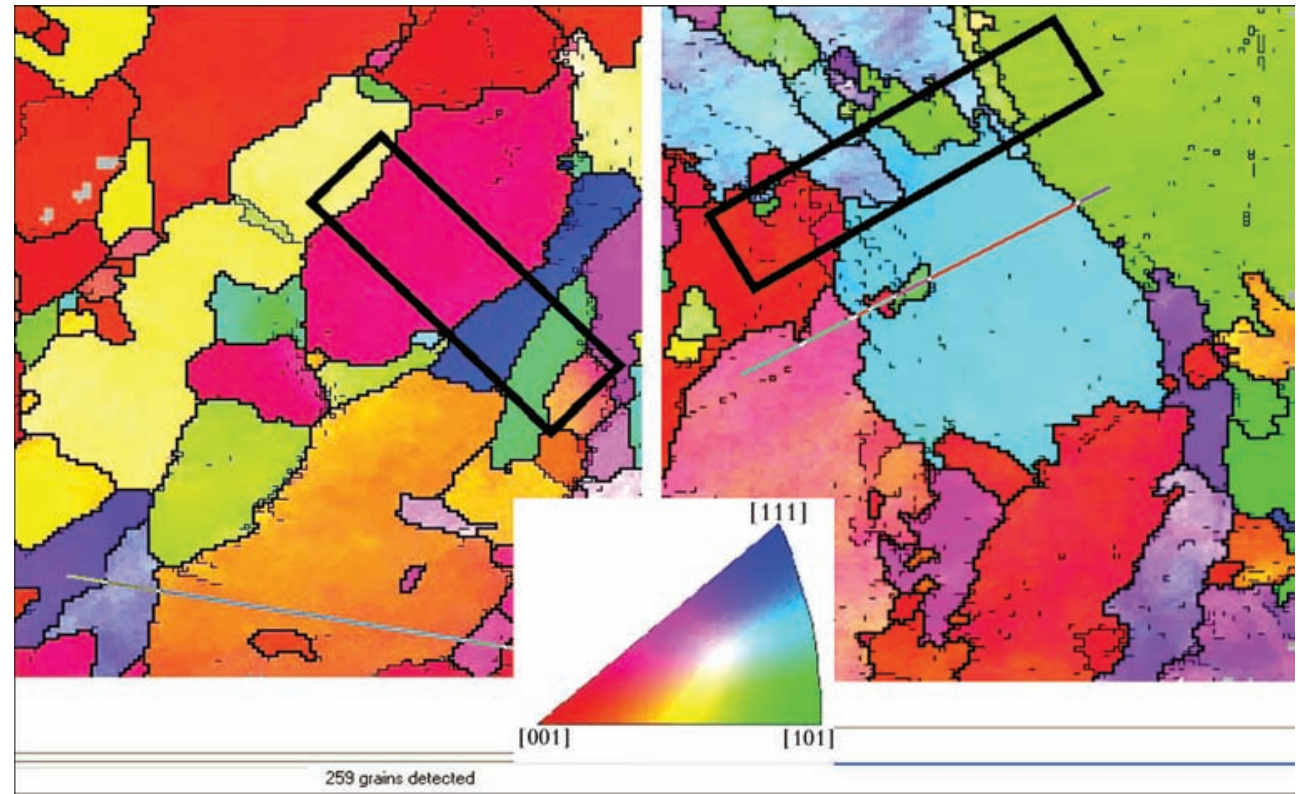

Figure 6. Fragments of crystallite orientation (inverse pole figure) of HAZ metal of welds, made with Inconel 52 (a) and Inconel 52MSS $(b)$ wires (rectangles mark points where microhardness measurement was performed)

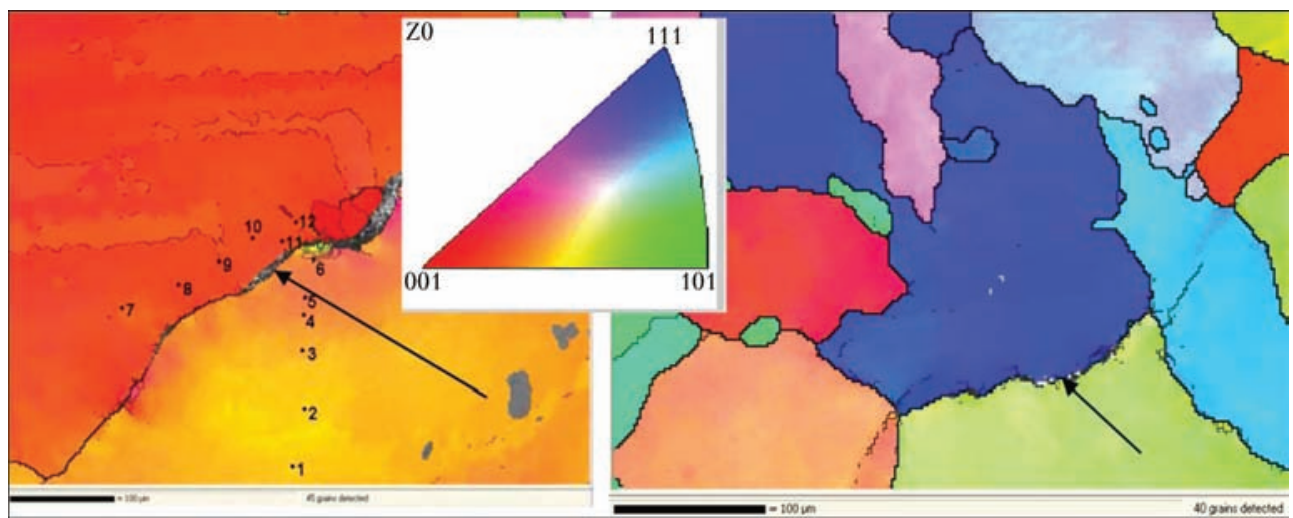

Figure 7. Crystallographic pattern of crack location in HAZ metal of Inconel 52 welded joint (arrows indicate cracks along grain boundaries) 
of polycrystalline nickel alloy and to assess plastic deformation localizing within several grains by microindentation method. Here, microhardness measurements were conducted in Micron-gamma microindentometer using 5 and $10 \mathrm{~g}$ load.

Measurement results showed microhardness values for Inconel 52 within 2.8-5.5 GPa, while microhardness for a sample made with Inconel 52MSS wire show a greater scatter of values from 2.9 to $7.0 \mathrm{GPa}$ (Figure 8 ).

\section{Conclusions}

Results of investigations of multilayer deposits, made with wires with different sensitivity to hot cracking, allowed showing that microstructural components and their change under the impact of welding thermal cycle significantly influence hot cracking resistance of welded joints.

In Inconel 52 welds, in which molybdenum and niobium content is minimum (total $\mathrm{Mo}+\mathrm{Nb}=0.7 \%$ ), chemical inhomogeneity decreases significantly, that promotes DDC development. At the same time, cracks are absent in welds of this type in individual regions of Inconel 52MSS weld, where niobium and molybdenum content rises 2 to 4 times, compared to total content $(\mathrm{Mo}+\mathrm{Nb}=6 \%)$.

It is established that the fine structure of weld metal at application of Inconel 52 wire is characterized by higher dislocation density, particularly at grain boundaries (of up to $\rho \sim 10^{11}-2.2 \cdot 10^{11} \mathrm{~cm}^{-2}$ ).

Absence of cracks in weld metal in the case of application of Inconel 52MSS wire is associated with uniform (without gradients) distribution of dislocation density, as well as lowering of SFE values (to $\gamma_{\mathrm{SFE}} \sim 0.091 \mathrm{~J} / \mathrm{cm}^{2}$ ).

DDC in welded joint HAZ propagate, as a rule, along high-angle grain boundaries.

Results of microhardness measurements in welds made with Inconel 52 wire showed values within 2.8$5.5 \mathrm{GPa}$, while that of a sample made with Inconel 52MSS wire have greater scatter of 2.9 to $7.0 \mathrm{GPa}$.

1. Panin, V.E., Egorushkin, V.E. (2008) Nonequilibrium thermodynamics of deformed solid as a multilevel system. Wave-corpuscle dualism of plastic shear. Fizich. Mezomekhanika, 11, 9-30.

2. Torres, E.A., Peternella, F.G., Caram, R. et al. (2010) In situ scanning electron microscopy high temperature deformation
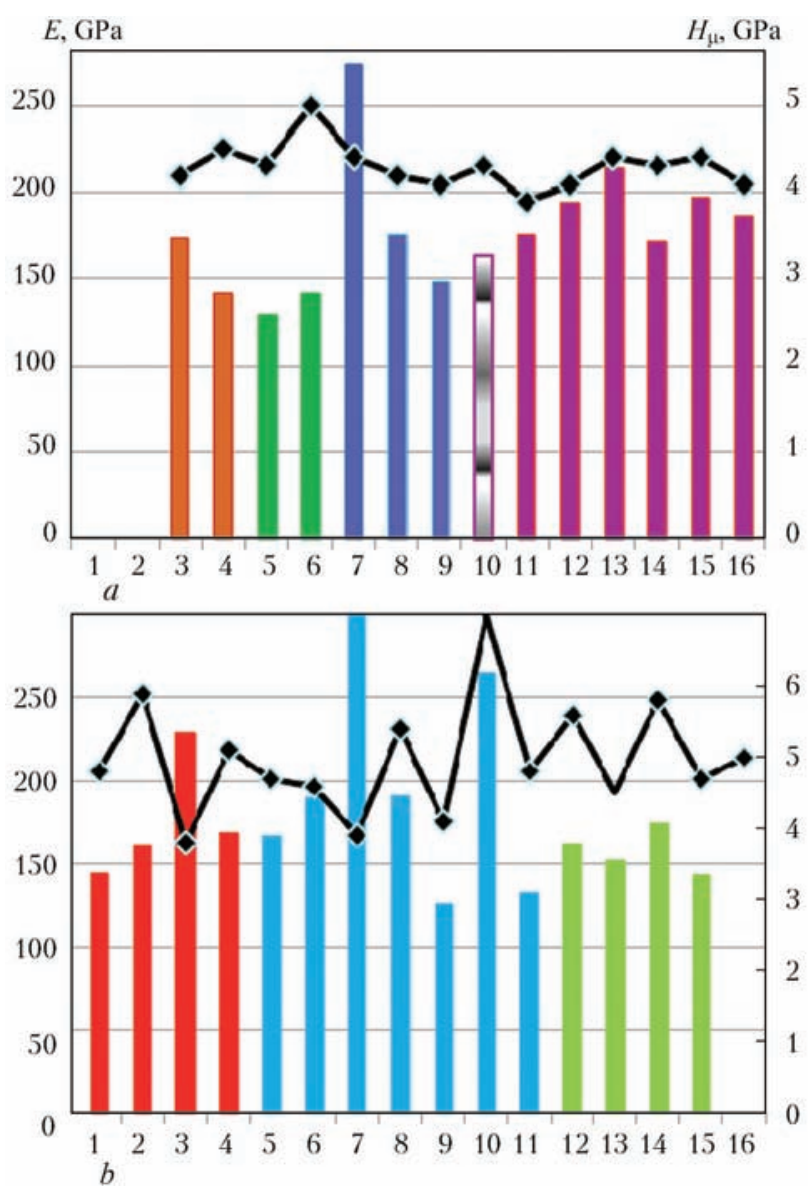

Figure 8. Microhardness and modulus of elasticity for HAZ of welded joints made with Inconel $52(a)$ and Inconel 52MSS (b) wire

experiments to study ductility dip cracking of $\mathrm{Ni}-\mathrm{Cr}-\mathrm{Fe}$ alloys. In: In-situ studies with phonons, neutrons and electrons scattering, 28. Berlin; Heidelberg: Springer.

3. Yushchenko, K., Savchenko, V., Chervyakov, N. et al. (2011) Comparative hot cracking evaluation of welded joints of alloy 690 using filler metals Inconel ${ }^{\circledR} 52$ and 52MSS. Welding in the World, 55(9/10), 28-35.

4. Lippold, J.C., Kotecki, D.J. (2005) Welding metallurgy and weldability of stainless steels. John Wiley \& Sons.

5. Yushchenko, K.A., Savchenko, V.S., Chervyakov, N.O. et al. (2014) Investigation of cracking susceptibility of austenitic material using PVR-test procedure. The Paton Welding J., 6/7, 10-13.

6. Hirsch, P., Howie, A., Nickolson, R. et al. (1968) Electron microscopy of thin crystals. Moscow: Mir.

7. Thomas, G. (1963) Electron microscopy of metals. Moscow: IL.

8. Gorelik, S.S., Rostarguev, L.N., Skakov, Yu.A. (1970) X-ray and electrooptic analyses. Moscow: Metallurgiya.

9. Collins, M.G., Ramirez, A.I., Lippold, J.C. (2004) An investigation of ductility-dip cracking in nickel-based weld metals. Pt 3. Welding J., 2, 39-49. 